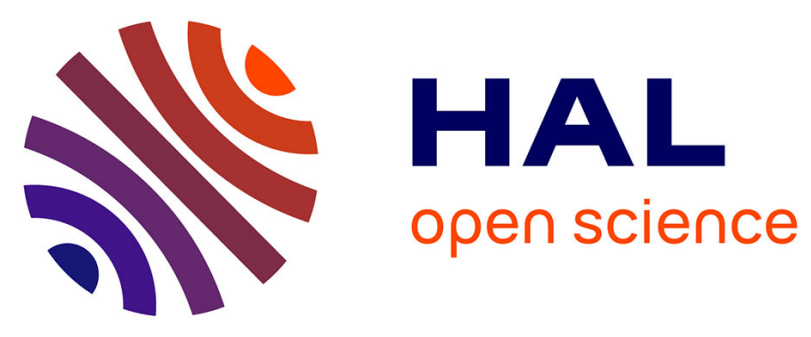

\title{
Validation of a New Classification Method of Postoperative Complications in Patients Undergoing Coronary Surgery
}

Eeva-Maija Kinnunen, Matti-Aleksi Mosorin, Andrea Perrotti, Vito G. Ruggieri, Peter Svenarud, Magnus Dalén, Francesco Onorati, Giuseppe Faggian, Giuseppe Santarpino, Daniele Maselli, et al.

\section{To cite this version:}

Eeva-Maija Kinnunen, Matti-Aleksi Mosorin, Andrea Perrotti, Vito G. Ruggieri, Peter Svenarud, et al.. Validation of a New Classification Method of Postoperative Complications in Patients Undergoing Coronary Surgery. Journal of Cardiothoracic and Vascular Anesthesia, 2015, In press. 10.1053/j.jvca.2015.09.019 . hal-01259442

HAL Id: hal-01259442

https://hal-univ-rennes1.archives-ouvertes.fr/hal-01259442

Submitted on 27 Jan 2016

HAL is a multi-disciplinary open access archive for the deposit and dissemination of scientific research documents, whether they are published or not. The documents may come from teaching and research institutions in France or abroad, or from public or private research centers.
L'archive ouverte pluridisciplinaire HAL, est destinée au dépôt et à la diffusion de documents scientifiques de niveau recherche, publiés ou non, émanant des établissements d'enseignement et de recherche français ou étrangers, des laboratoires publics ou privés. 


\section{Validation of a New Classification Method of Postoperative Complications in Patients Undergoing Coronary Surgery}

Eeva-Maija Kinnunen, ${ }^{1}$ MD, Matti-Aleksi Mosorin, ${ }^{1} \mathrm{MD}$, Andrea Perrotti, ${ }^{2} \mathrm{MD}$, Vito G. Ruggieri, ${ }^{3}$ $\mathrm{MD}, \mathrm{PhD}$, Peter Svenarud, ${ }^{4} \mathrm{MD}, \mathrm{PhD}$, Magnus Dalén, ${ }^{4} \mathrm{MD}$, Francesco Onorati, ${ }^{5} \mathrm{MD}, \mathrm{PhD}$, Giuseppe Faggian, ${ }^{5} \mathrm{MD}, \mathrm{PhD}$, Giuseppe Santarpino, ${ }^{6} \mathrm{MD}$, PhD, Daniele Maselli, ${ }^{7} \mathrm{MD}$, Carmelo Dominici, ${ }^{7} \mathrm{MD}$, Saverio Nardella, ${ }^{7} \mathrm{MD}$, Francesco Musumeci, ${ }^{8} \mathrm{MD}$, Riccardo Gherli, ${ }^{8} \mathrm{MD}$, Giovanni Mariscalco, ${ }^{9}$ $\mathrm{MD}, \mathrm{PhD}$, Nicola Masala, ${ }^{9} \mathrm{MD}$, Antonino S. Rubino, ${ }^{10} \mathrm{MD}$, Carmelo Mignosa, ${ }^{10} \mathrm{MD}$, Marisa De Feo, ${ }^{11}$ $\mathrm{MD}, \mathrm{PhD}$, Alessandro Della Corte, ${ }^{11} \mathrm{MD}, \mathrm{PhD}$, Ciro Bancone, ${ }^{11} \mathrm{MD}$, Sidney Chocron, ${ }^{2} \mathrm{MD}, \mathrm{PhD}$, Giuseppe Gatti, ${ }^{12}$ MD, Tatu Juvonen, ${ }^{1}$ MD, PhD Fausto Biancari, ${ }^{1} \mathrm{MD}, \mathrm{PhD}$.

1. Department of Surgery, Oulu University Hospital, Oulu, Finland;

3. Department of Thoracic and Cardio-Vascular Surgery, University Hospital Jean Minjoz, Besançon, France;

2. Division of Cardiothoracic and Vascular Surgery, Pontchaillou University Hospital, Rennes, France;

4. Department of Molecular Medicine and Surgery, Department of Cardiothoracic Surgery and Anesthesiology, Karolinska Institutet, Karolinska University Hospital, Stockholm, Sweden;

5. Division of Cardiovascular Surgery, Verona University Hospital, Verona, Italy;

6. Department of Cardiac Surgery, Klinikum Nürnberg, Paracelsus Medical University, Nuremberg, Germany;

7. Department of Cardiac Surgery, St. Anna Hospital, Catanzaro, Italy;

8. Unit of Cardiac Surgery, Department of Cardiosciences, Hospital S. Camillo-Forlanini, Rome, Italy;

9. Department of Cardiovascular Sciences, Clinical Science Wing, University of Leicester, Glenfield Hospital, Leicester, UK;

10. Centro Cuore Morgagni, Pedara, Italy;

11. Division of Cardiac Surgery, Department of Cardiothoracic Sciences, Second University of Naples, Naples, Italy;

12. Division of Cardiac Surgery, Ospedali Riuniti, Trieste, Italy.

For correspondence: Prof. Fausto Biancari, Department of Surgery, Oulu University Hospital,

P.O. Box 21, 90029 Oulu, Finland.

Tel.: +358 407333 973;

Fax: + 3588315 2813;

E-mail: faustobiancari@yahoo.it 


\section{Abstract}

Objective: We aimed to validate the E-CABG classification of postoperative complications in patients undergoing coronary artery bypass grafting (CABG).

Design: Retrospective, observational study.

Setting: University hospital.

Participants: 2764 patients with severe coronary artery disease. Complete baseline, operative and postoperative data were available for who underwent isolated CABG.

Interventions: Isolated CABG.

Measurements and Main Results: The E-CABG complication classification was employed to stratify the severity and prognostic impact of postoperative adverse events. Primary outcome end-points were 30-day, 90-day and long-term all-cause mortality. Secondary outcome end-point was the length of intensive care unit stay. Both the E-CABG complication grades and additive score were predictive of 30-day (area under the ROC curve $0.866,95 \% \mathrm{Cl} 0.829-0.903$ and $0.876,95 \% \mathrm{Cl} 0.844-$ 0.908, respectively) and 90-day (area under the ROC curve $0.850,95 \% \mathrm{Cl} 0.812-0.887$ and 0.863 , $95 \% \mathrm{Cl}$ 0.829-0.897, respectively) all-cause mortality. The complication grades were independent predictors of increased mortality at actuarial (Log-rank: $p<0.0001)$ and adjusted analysis ( $p<0.0001$, grade 1: HR 1.757, 95\%Cl 1.111-2.778, grade 2: 2.704, 95\%Cl 1.664-4.394; grade 3: $5.081,95 \mathrm{Cl} \% 3.148-8.201)$. When patients who died within 30 days were excluded from the analysis, this grading method was still associated with late mortality $(p<0.0001)$. The grading method $(p<0.0001)$ and the additive score $(r h o, 0.514 ; p<0.0001)$ were predictive of the length intensive care unit stay. 
Conclusions: The E-CABG postoperative complication classification seems to be a promising tool for stratifying the severity and prognostic impact of postoperative complications in patients undergoing cardiac surgery.

\section{Abstract word count: 235 words}

Key words: Coronary artery bypass; cardiac surgery; complication; classification.

\section{INTRODUCTION}

Adult cardiac surgery is associated with significant postoperative mortality and morbidity.

Moreover, a number of postoperative complications are rather frequent and may compromise the recovery of patients undergoing cardiac surgery. ${ }^{1,2}$ Such complications also increase the burden of resource use $\mathrm{e}^{1,2}$ and may affect late survival. ${ }^{3-7}$ Few grading methods for complications after major surgery have been developed to assess the quality of surgical treatment. ${ }^{8,9}$ However, these grading systems are not applicable to patients undergoing cardiac surgery and therefore a specific grading method for these patients is needed. The E-CABG (European multicenter study on coronary artery bypass grafting) investigators recently proposed a classification of postoperative complications as a part of their study protocol. ${ }^{10}$ The present study was planned to assess the ability of the E-CABG complication classification in predicting early and long-term mortality as well as length of intensive care unit stay of patients undergoing isolated coronary artery bypass grafting (CABG). 


\section{METHODS}

Patient population and data collection

The present study included 2764 consecutive patients who underwent isolated CABG from June 2006 to December 2013 at the Oulu University Hospital, Finland. The study included elective, urgent and emergency operations carried out with either off-pump or on-pump technique. Patients' characteristics and operative data are summarized in Table 1. Definition criteria of baseline characteristics are according to the EuroSCORE criteria. ${ }^{11}$

Complete pre- intra- and postoperative data were available in all these patients as obtained from institutional electronic cardiac surgery database collecting baseline and operative data as well as data on immediate postoperative adverse events. These data were collected by two research nurses and three colleagues. The senior author (FB) has checked all the data along the years. In 2014 and 2015, this database was again checked by two researchers (EMK and MAM). Twentyeight patients without data on serum levels of creatinine were still included in this analysis as in most of the cases they died immediately after surgery and their postoperative creatinine level was not checked. The amount of transfused blood products such as red blood cells (RBCs), platelets and solvent/detergent-treated plasma (Octaplas; Octapharma AG, Lachen, Switzerland) was retrieved from a prospective electronic hospital registry collecting data on any transfusion of blood products. These blood products were administered intraoperatively and throughout the inhospital stay. Data on the amount of postoperative blood losses were retrieved from a prospective electronic registry of our intensive care unit. Glomerular filtration rate (eGFR) was estimated using the Modification of Diet in Renal Disease (MDRD) formula. ${ }^{12}$ Clinical variables were defined according to the EuroSCORE II definition criteria. ${ }^{12}$ 
Data on patients' death were retrieved from Statistics Finland (Tilastokeskus) which collects the certificates of death of all inhabitants of Finland. The data for this study were provided up to December 31st, 2013. We assume that there are no missing data on immediate and late death of this study population.

Operative Techniques

Intermittent antegrade and retrograde blood cardioplegia with $\mathrm{KCl}$ and $\mathrm{MgCl}$ at a temperature ranging from 10 to $16^{\circ} \mathrm{C}$ was delivered during on-pump CABG. Epiaortic ultrasound was performed according to the surgeon's preference. The ascending aorta was clamped in case of atherosclerotic lesion involving the lateral and/or anterior wall of the ascending aorta. Proximal anastomoses were sutured to the ascending aorta during side clamping or cross-clamping when it was considered safe. Octopus stabilizer (Medtronic, Minneapolis, MN) as well as intracoronary shunts were routinely used in patients who underwent off-pump CABG.

E-CABG postoperative complication classification method

E-CABG is a European multicenter study currently recruiting patients undergoing isolated CABG. The study protocol of this study with detailed definition criteria of baseline, operative and postoperative variables has been published previously. ${ }^{10}$ The E-CABG investigators proposed a classification method to stratify the adverse outcome events occurring in these patients. 
Twenty-four investigators selected and stratified the severity burden of 25 complications or interventions for their treatment with potentially negative prognostic impact on the course of patients undergoing adult cardiac surgery. Each investigator assigned a score of 0-10 in regards of the expected negative impact on outcome of each of these adverse events/interventions. A score of 10 was supposed to measure the worst postoperative complication, i.e. patient's death. The medians of scores for each complication/intervention were used to stratify the prognostic importance of these adverse events and to develop a four-grade classification of postoperative complications (Tab. 2). In case of multiple adverse events occurring in a particular patient, the event with the highest score defines the grade to which the patient belongs to. The median scores are used as an additive score as well.

\section{Outcome endpoints}

The main outcome measures of this study were all-cause 30-day, 90-day and long-term mortality. The secondary outcome end-point was the length of intensive care unit stay. We did not consider the length of in-hospital stay as an outcome measure as the timing of discharge of these patients reflects the availability of beds at rehabilitation clinics.

Ethical considerations

This study was approved by the Institutional Review Board of the Oulu University Hospital and it was not financially supported. 
Statistical analysis was performed with the SPSS v. 22.0 statistical software (IBM Corporation, 1 New Orchard Road Armonk, New York 10504-1722, United States). No attempt to replace missing values was made. Fisher exact test, Chi-square test, Mann-Whitney and Kruskal-Wallis tests were used for univariate analysis. Correlation between continuous and ordinal variables was estimated by the Spearman's test. Survival analysis at 90 days was performed including only patients with a potential follow-up longer than 3 months. C-statistics were calculated to assess the predictive ability of the E-CABG complication classification either as additive score or grades. Kaplan-Meier method was used to estimate late survival. Cox proportional hazards analysis was performed to adjust the E-CABG complication grades for baseline and operative variables potentially associated with poor late survival. These variables were age, eGFR, gender, diabetes, hypertension, prior stroke, neurological dysfunction, extracardiac arteriopathy, previous percutaneous coronary intervention, previous cardiac surgery, recent myocardial infarction, pulmonary disease, left ventricular ejection fraction classes, dialysis, elective/urgent/emergency operation, unstable angina requiring nitrates at operating room arrival, critical preoperative status, systolic pulmonary pressure, off-pump surgery, number of distal anastomoses and any mammary artery graft. Because of imbalance in baseline and operative characteristics of patients in different E-CABG classification grades, probabilities (propensity scores) estimated by multinomial regression analysis were employed to adjust the risk of early and late mortality in these patients with different E-CABG grades (multiple propensity score adjusted analysis). Propensity scores were calculated by a regression model entering all baseline and operative variables listed above. All tests were two-sided with the alpha level set at 0.05 for statistical significance. 


\section{RESULTS}

Patients' characteristics in the overall study population as well as in each E-CABG grade are summarized in Table 1. Table 2 summarizes the proportion of patients included in each E-CABG complication grade as well as the prevalence of postoperative adverse events in this series. The inhospital mortality was $2.4 \%$. The median additive score for each grade indicated that within increasing grades of complications also the number of complications increased markedly (grade 1, 4.0; grade 2, 10.0; grade 3, 21.0).

This grading method was predictive of the length of stay in the intensive care unit (grade 0 , 1.2 \pm 0.6 days; grade $1,1.6 \pm 1.1$ days; grade $2,2.9 \pm 2.1$ days; grade $3,4.9 \pm 5.2$ days, Kruskal-Wallis's test: $p<0.0001)$. The E-CABG complication additive score also correlated significantly with the length of stay in the intensive care unit (Spearman's test: rho, $0.514 ; p<0.0001)$.

The E-CABG complication grades were predictive of 30 -day (grade $0,0 \%$; grade $1,0.4 \%$; grade 2 , $1.7 \%$; grade $3,14.5 \%, p<0.0001$ ) and of 90 -day mortality (grade $0,2 \%$; grade $1,1.1 \%$; grade 2 , 3.7\%; grade 3, 21.5\%, $\mathrm{p}<0.0001)$. Similarly, increasing quintiles of the E-CABG complication score were associated with increased 30 -day mortality $(0 \%, 0.3 \%, 1.1 \%, 3.1 \%, 12.6 \%, p<0.0001)$ as well as 90 -day mortality $(0.2 \%, 0.6 \%, 1.3 \%, 3.9 \%, 15.0 \%, p<0.0001)$.

Receiver operating characteristics (ROC) analysis confirmed that the E-CABG complication score was predictive of 30-day (area under the ROC curve $0.876,95 \% \mathrm{Cl} 0.844-0.908$ ) and 90-day (area under the ROC curve $0.863,95 \% \mathrm{Cl} 0.829-0.897$, Fig. 1) all-cause mortality. Since the grading method is the result of a breakdown of this additive score, ROC analysis was performed also for the E-CABG complication grades and showed that these were predictive of 30-day (area under the ROC curve $0.866,95 \% \mathrm{Cl} 0.829-0.903$ ) and 90 -day (area under the ROC curve $0.850,95 \% \mathrm{Cl} 0.812$ 0.887) all-cause mortality. 
The E-CABG complication grades were independent predictors of increased mortality at KaplanMeier (at 5 years: grade 0, 5.5\%; grade 1, 11.1\%; grade 2, 23.1\%; grade 3, 35.3\%, Log-rank: p<0.0001) (Fig. 2) and Cox regression adjusted analysis (2651 patients included in the multivariate model; $p<0.0001$, grade 1: HR 1.757, 95\%Cl 1.111-2.778, grade 2: 2.704, 95\%Cl 1.664-4.394; grade 3: 5.081, 95Cl\% 3.148-8.201) (Tab. 2, Fig. 3).

When patients who died within 30 days were excluded from the analysis, this grading method was still associated with late mortality (2562 patients included in the multivariate model; $p<0.0001$, grade 1: HR 1.760, 95\%Cl 1.1356-2.283, grade 2: $2.936,95 \% \mathrm{Cl} 1.798-4.794$; grade 3: $3.209,95 \mathrm{Cl} \%$ 1.929-5.338).

Figure 4 summarizes the unadjusted risk estimates of any early and late mortality for each postoperative adverse event. This analysis confirmed that the adverse events included among grade 3 complications were associated with a formidable risk of death. Postoperative use of intraaortic balloon pump was associated with a very high mortality, likely because extracorporeal membrane oxygenation was not in use in this series. Multivariate analysis of the prognostic impact of these adverse events was not performed because of the risk of overfitting. 


\section{DISCUSSION}

The present analysis showed that the E-CABG complication classification performed well when used either as a four-grade classification system or as additive score. In fact, both the E-CABG complication grades and score were predictive of increased early and late mortality as well as of the length of stay in the intensive care unit in patients undergoing isolated CABG. As seen in Figure 4, particularly the adverse events included among grade 3 complications were associated with a remarkably increased risk of death. Mortality in patients with postoperative use of intra-aortic balloon pump was very high, possibly due to their severely depressed hemodynamic conditions of these patients. Indeed, our institutional policy is to use intra-aortic balloon pump only after CABG is accomplished and patient has low cardiac output despite optimal inotropic support.

Extracorporeal membrane oxygenation was not used in this series.

We did not perform a multivariate analysis to adjust the postoperative complications for baseline and operative characteristics because this model would have been too complex and might have led to overfitting. However, risk estimates of several postoperative complications appeared such large in univariate analysis that it is not plausible that this was caused solely by bias. Also previous studies have reported significant mortality associated with postoperative complications such as increased RBC transfusion, ${ }^{13,14}$ acute kidney injury, ${ }^{4,6}$ mediastinitis, ${ }^{7}$ gastrointestinal complications, ${ }^{15,16}$ use of IABP ${ }^{17,18}$ and atrial fibrillation. ${ }^{3}$ Welsby et al. investigated patients undergoing cardiac surgery with cardiopulmonary bypass and found that, after adjusting for preoperative and intraoperative risk factors, the occurrence of non-cardiac complications only and cardiac complications with other organ involvement significantly increased mortality as well as the length of stay in the hospital and intensive care unit when compared with cardiac complications only. ${ }^{19}$ 
In addition to the potential independent effect of complications on patients' survival, there seemed to be an interaction between postoperative adverse events. Indeed, the median additive score for each grade showed that within increasing grades of complications also the number of complications increased significantly as indicated by increased additive score, which was particularly high in Grade 3.

The present study showed that a number of complications in lower grades of the classification are not likely to affect patients' survival (Fig. 4) even though also opposite results have been reported. ${ }^{5}$ However, even complications that are considered less severe may cause discomfort to the patient and increase the costs for their treatment. Moreover, the synergistic effect of multiple, even minor, adverse events may also make the lower complication grades of clinically significance as seen in the adjusted analyses (Tab. 2).

An important finding emerging from this analysis was that the risk of death is not limited to the inhospital stay: indeed, patients are discharged and die shortly after surgery. In patients classified as Grade 3, 30-day mortality was $14.5 \%$ and 90 -day mortality $21.5 \%$. Such a high mortality is not acceptable and therefore, considering the potentially preventable nature of a number of these postoperative complications, preventive methods should be employed to improve the outcome of these patients. Future studies investigating the predictors of Grade 3 complications may identify patients at high risk and indicate different treatment strategies.

Supporting the results of the present study, previous studies emphasized that in-hospital mortality may not be the most adequate variable to measure the quality of care in patients undergoing CABG. ${ }^{20,21}$ Silber et al. compared 57 American hospitals and observed that reported complication rates did not correlate with rates of in-hospital mortality. ${ }^{20}$ Instead, several hospital characteristics generally associated with a higher quality of treatment were associated with rather low mortality rates, but higher complication rates. ${ }^{20}$ 
Also Ghali et al. concluded that complications after CABG are common and may provide more informations about hospital quality than in-hospital mortality rates. ${ }^{21}$

A number of limitations which may affect the results of this study should be acknowledged. The retrospective nature of this study is an important limitation of this analysis. However, even if there are some retrospectively collected data, data on important outcome end-points were retrieved from prospective electronic registries which can be considered reliable. Furthermore, data on patient's death are retrieved form a national registry which collects data on all Finnish population. This study assessed the prognostic impact of the E-CABG complication classification in patients undergoing isolated CABG at a single institution and including patients who underwent either offpump or on-pump surgery. Therefore, this classification method should be validated in patients operated in other institutions, particularly in those undergoing cardiac procedures other than isolated CABG. 
CONCLUSIONS

The E-CABG complication classification seems to be a promising tool for stratification of the severity and prognostic effect of postoperative complications in patients undergoing isolated CABG. This classification method may be of benefit in clinical research in this field. 


\section{References}

1. Brown PP, Kugelmass AD, Cohen DJ, et al: The frequency and cost of complications associated with coronary artery bypass grafting surgery: results from the United States Medicare program. Ann Thorac Surg 85: 1980-1986, 2008

2. Hall RE, Ash AS, Ghali WA, Moskowitz MA: Hospital cost of complications associated with coronary artery bypass graft surgery. Am J Cardiol 79: 1680-1682, 1997

3. Phan $\mathrm{K}, \mathrm{Ha} \mathrm{HS}$, Phan S, Medi C, et al: New-onset atrial fibrillation following coronary bypass surgery predicts long-term mortality: a systematic review and meta-analysis. Eur J Cardiothorac Surg 2015 (in press).

4. Hansen MK, Gammelager $\mathrm{H}$, Jacobsen $\mathrm{CJ}$, et al: Acute kidney injury and long-term risk of cardiovascular events after cardiac surgery: a population-based cohort study. J Cardiothorac Vasc Anesth 29: 617-625, 2015.

5. Filsoufi F, Castillo JG, Rahmanian PB, et al: Epidemiology of deep sternal wound infection in cardiac surgery. J Cardiothorac Vasc Anesth 23: 488-494, 2009

6. Han SS, Shin N, Baek SH, et al: Effects of acute kidney injury and chronic kidney disease on longterm mortality after coronary artery bypass grafting. Am Heart J 169: 419-425, 2015

7. Risnes I, Abdelnoor M, AlmdahI SM, Svennevig JL: Mediastinitis after coronary artery bypass grafting risk factors and long-term survival. Ann Thorac Surg 89: 1502-1509, 2010

8. Dindo D, Demartines N, Clavien PA: Classification of surgical complications: a new proposal with evaluation in a cohort of 6336 patients and results of a survey. Ann Surg 240: 205-213, 2004

9. Strasberg SM, Linehan DC, Hawkins WG. The Accordion severity grading system of surgical complications. Ann Surg 250: 177-186, 2009 
10. Biancari F, Ruggieri VG, Perrotti A, et al: European multicenter study on coronary artery bypass grafting (E-CABG registry): study protocol for a prospective clinical registry and proposal of classification of postoperative complications. J Cardiothorac Surg 10: 90, 2015

11. Nashef SA, Roques F, Sharples LD, et al: EuroSCORE II. Eur J Cardiothorac Surg 41: 734-744, 2012

12. Levey AS, Bosch JP, Lewis JB, Greene T, Rogers N, Roth D: A more accurate method to estimate glomerular filtration rate from serum creatinine: a new prediction equation. Modification of Diet in Renal Disease Study Group. Ann Intern Med 130: 461-70, 1999

13. Murphy GJ, Reeves BC, Rogers CA, Rizvi SI, Culliford L, Angelini GD: Increased mortality, postoperative morbidity, and cost after red blood cell transfusion in patients having cardiac surgery. Circulation 116: 2544-2552, 2007

14. Vivacqua A, Koch CG, Yousuf AM, et al: Morbidity of bleeding after cardiac surgery: is it blood transfusion, reoperation for bleeding, or both? Ann Thorac Surg 91: 1780-1790, 2011

15. Mangi AA, Christison-Lagay ER, Torchiana DF, et al: Gastrointestinal complications in patients undergoing heart operation: an analysis of 8709 consecutive cardiac surgical patients. Ann Surg 241: 895-901, 2005

16. Filsoufi F, Rahmanian PB, Castillo JG, et al: Predictors and outcome of gastrointestinal complications in patients undergoing cardiac surgery. Ann Surg 246: 323-329, 2007

17. Arafa OE, Pedersen TH, Svennevig JL, et al: Intraaortic balloon pump in open heart operations: 10-year follow-up with risk analysis. Ann Thorac Surg 65: 741-747, 1998

18. Saura E, Savola J, Gunn J: A 6-year single-center experience of intra-aortic balloon pump treatment-retrospective analysis of 223 patients. J Cardiothorac Vasc Anesth 2015 (in press) 
19. Welsby IJ, Bennett-Guerrero E, Atwell D, et al: The association of complication type with mortality and prolonged stay after cardiac surgery with cardiopulmonary bypass. Anesth Analg 94: $1072-1078,2002$

20. Silber JH, Rosenbaum PR, Schwartz JS, et al: Evaluation of the complication rate as a measure of quality of care in coronary artery bypass graft surgery. JAMA 274: 317-323, 1995

21. Ghali WA, Hall RE, Ash AS, et al: Evaluation of complication rates after coronary artery bypass surgery using administrative data. Methods Inf Med 37: 192-200, 1998 


\section{Legend to figures}

Figure 1. Receiver operating characteristics curve of E-CABG complication classification score in predicting 30-day all-cause mortality.

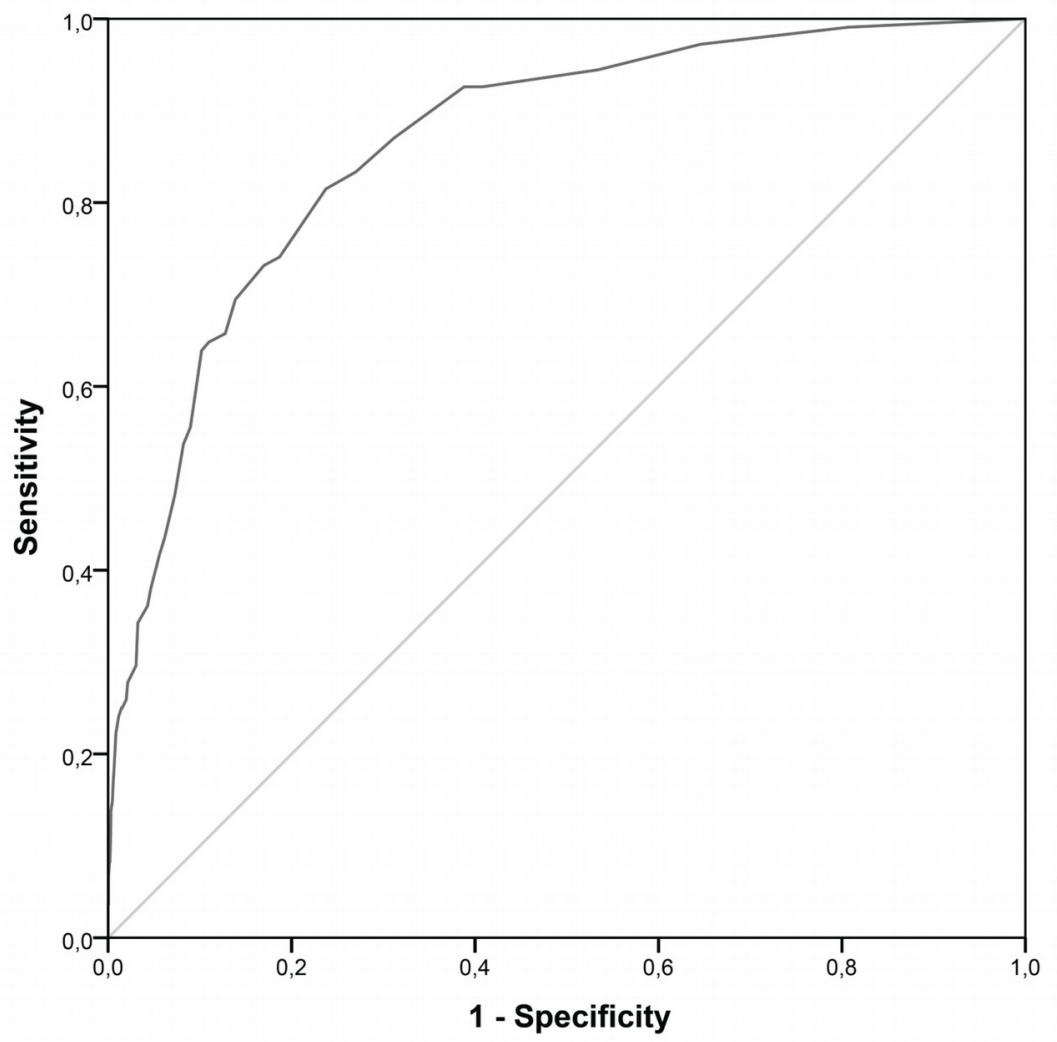


Figure 2. Kaplan-Meier estimates of all-cause mortality according to different E-CABG complication classification grades (log-rank: $p<0.0001)$.

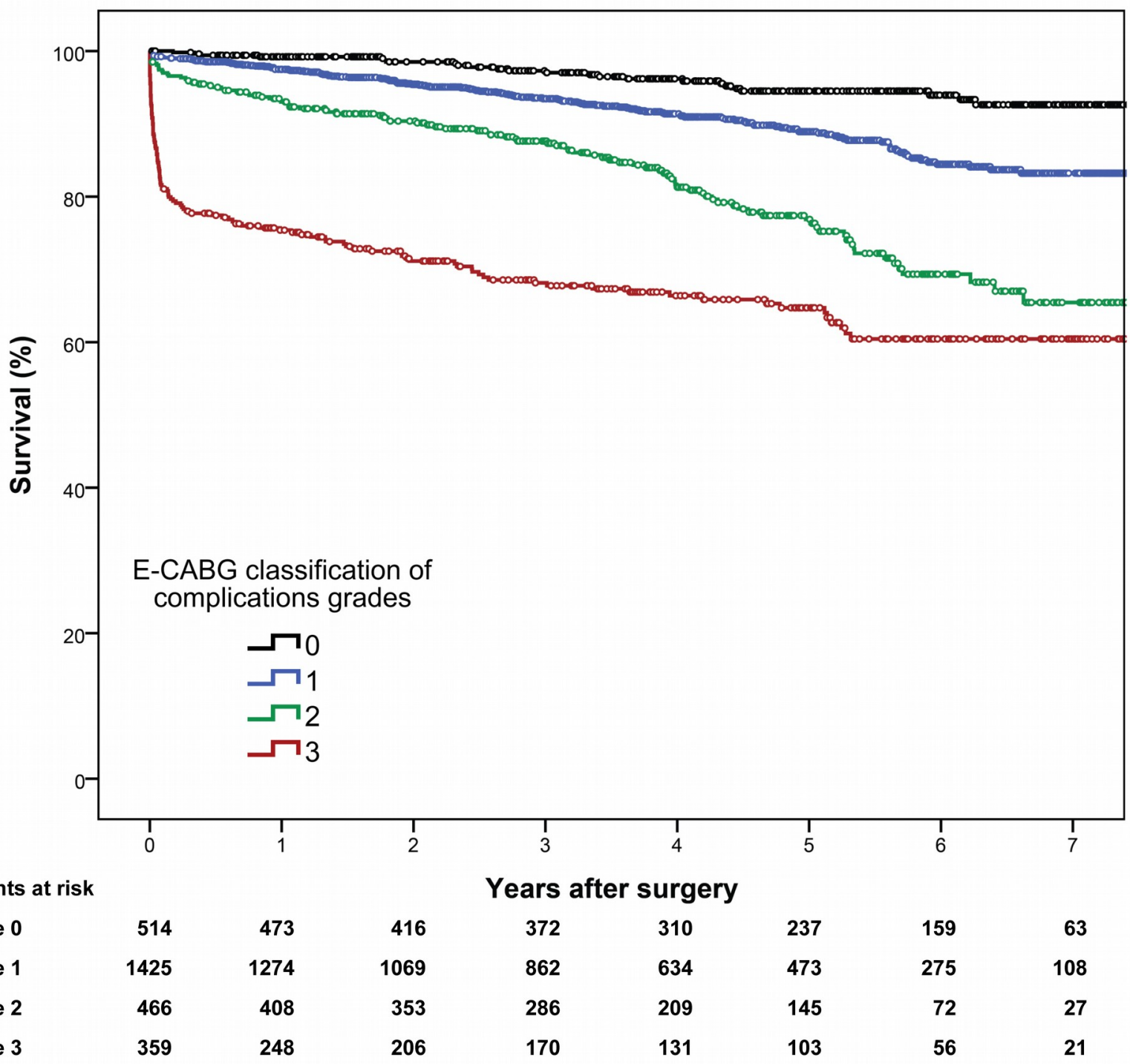


Figure 3. Adjusted Cox proportional hazards estimates of all-cause mortality according to different E-CABG complication classification grades ( $p<0.0001$, grade 1: HR 1.757, 95\%Cl 1.111-2.778, grade 2: $2.704,95 \% \mathrm{Cl} 1.664-4.394$; grade 3: 5.081, 95Cl\% 3.148-8.201).

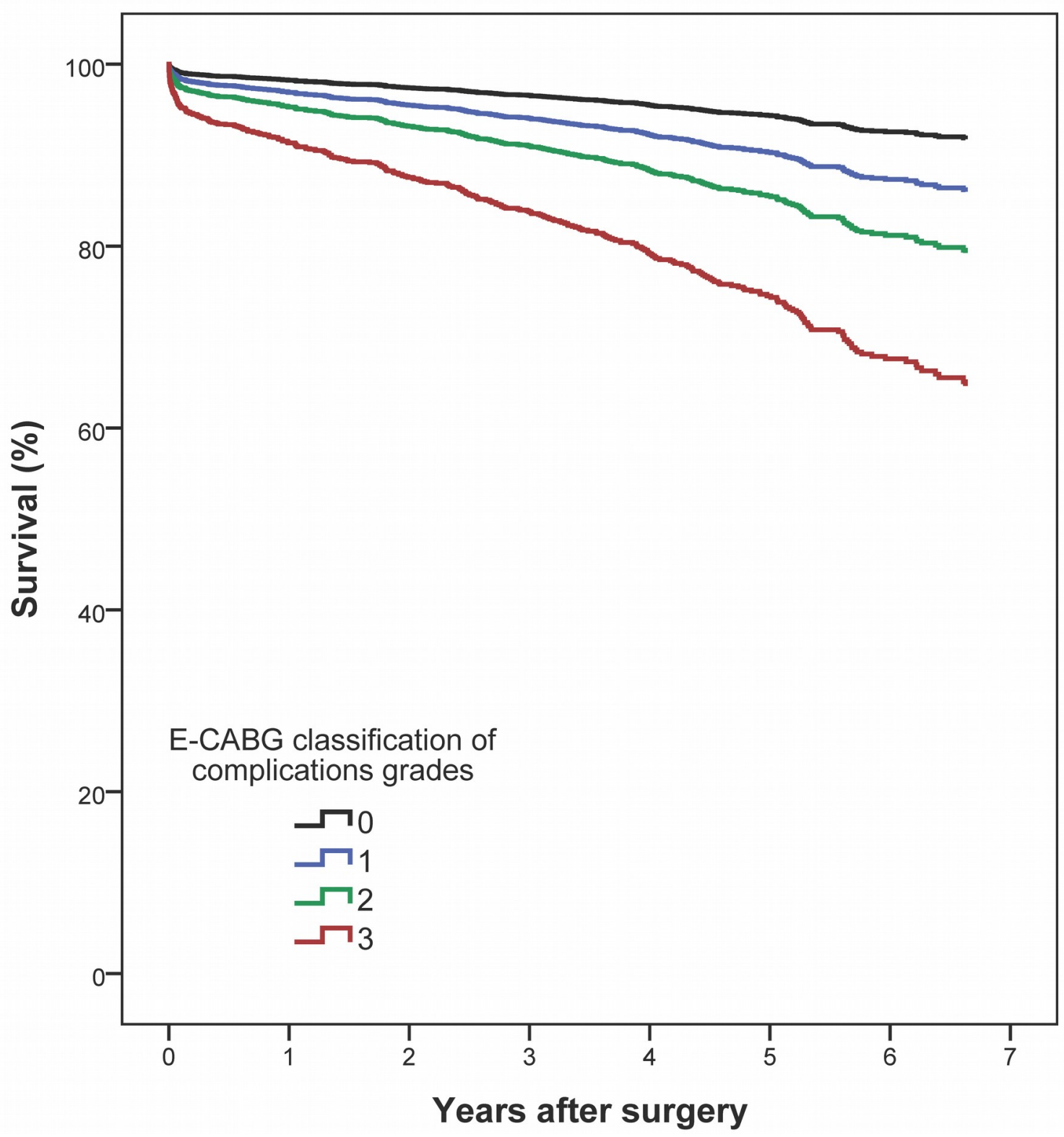


Figure 4. Unadjusted estimates of all-cause mortality according to different postoperative adverse events included in the E-CABG complication classification. IABP: intra-aortic balloon pump; RBC: red blood cell; CABG: coronary artery bypass grafting; PCI: percutaneous coronary intervention; ECMO: extracorporeal membrane oxygenation; HR: hazard ratio; $\mathrm{Cl}$ : confidence interval.

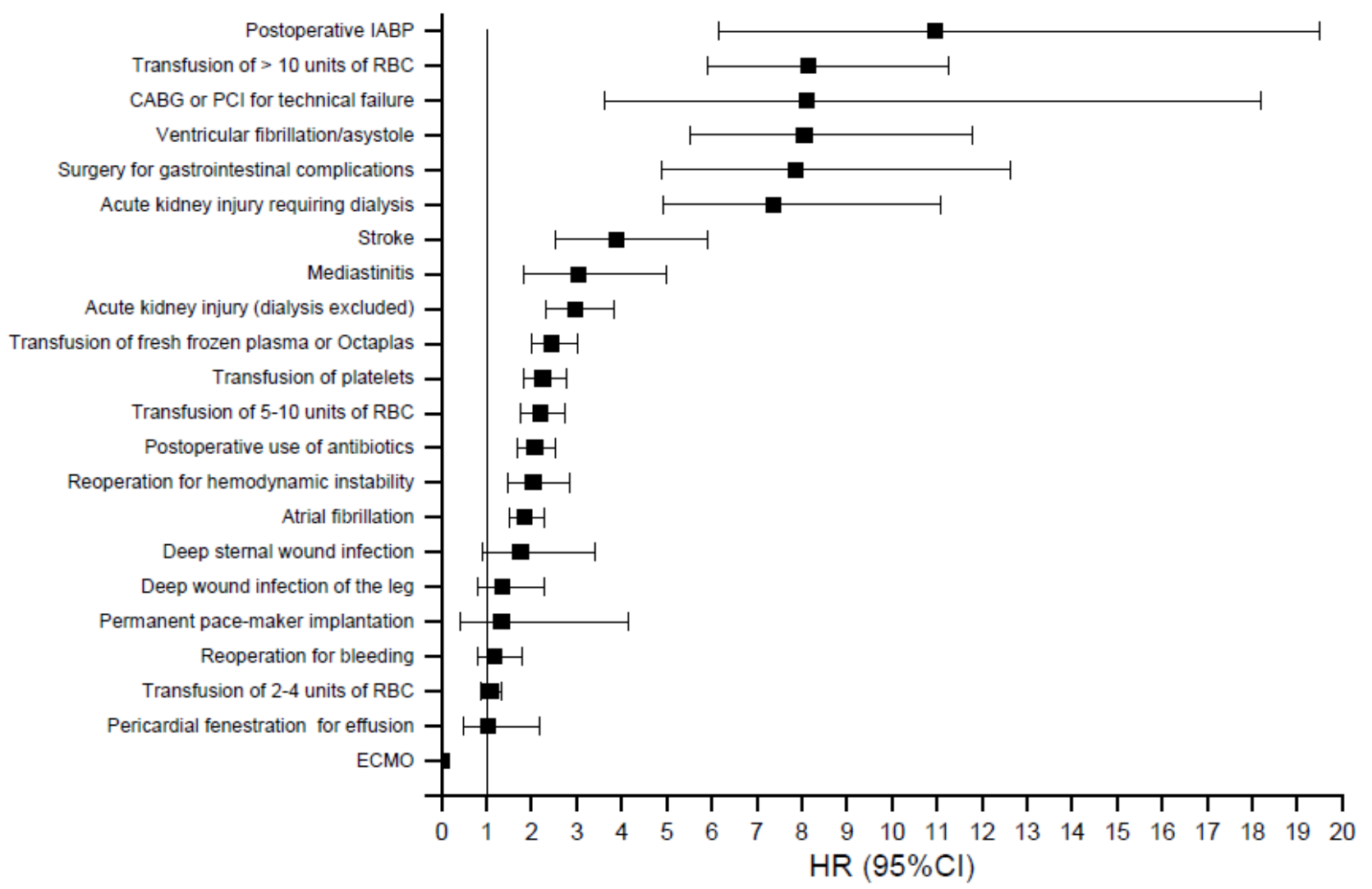


Table 1. Baseline and operative characteristics and in-hospital deaths of the study population and subgroups according to the ECABG grading.

\begin{tabular}{|c|c|c|c|c|c|c|}
\hline & $\begin{array}{l}\text { Overall series } \\
n=2764\end{array}$ & $\begin{array}{l}\text { Grade } 0 \\
n=514\end{array}$ & $\begin{array}{l}\text { Grade } 1 \\
n=1425 \\
\end{array}$ & $\begin{array}{l}\text { Grade } 2 \\
n=466\end{array}$ & $\begin{array}{l}\text { Grade } 3 \\
n=359\end{array}$ & P-value \\
\hline Age (years) & $67.0 \pm 9.1$ & $63.3 \pm 8.4$ & $67.1 \pm 8.9$ & $69.6 \pm 9.4$ & $68.1 \pm 8.7$ & $<0.001$ \\
\hline Female & $582(21.1)$ & $60(11.7)$ & $289(20.3)$ & $151(32.4)$ & $82(22.8)$ & $<0.001$ \\
\hline Pulmonary disease & 274 (9.9) & $48(9.3)$ & $126(8.8)$ & $52(11.2)$ & $48(13.4)$ & 0.05 \\
\hline Diabetes & $788(28.5)$ & $120(23.3)$ & $381(26.7)$ & $176(37.8)$ & $111(30.9)$ & $<0.001$ \\
\hline Hypertension & $1547(56.0)$ & $269(52.3)$ & 794 (55.7) & $280(60.1)$ & $204(56.8)$ & 0.11 \\
\hline Stroke & $95(3.4)$ & $10(1.9)$ & $46(3.2)$ & $20(4.3)$ & $19(3.4)$ & 0.04 \\
\hline Neurologic dysfunction & $50(1.8)$ & $1(0.2)$ & $32(2.2)$ & $8(1.7)$ & $9(2.5)$ & 0.02 \\
\hline Extracardiac arteriopathy & $265(9.6)$ & $33(6.4)$ & $117(8.2)$ & $59(12.7)$ & $56(15.6)$ & $<0.001$ \\
\hline eGFR $\left(\mathrm{mL} / \mathrm{min} / 1.73 \mathrm{~m}^{2}\right)$ & $86.1 \pm 25.2$ & $92.3 \pm 20.8$ & $87.0 \pm 23.1$ & $81.2 \pm 29.4$ & $79.9 \pm 30.2$ & $<0.001$ \\
\hline Dialysis & $22(0.8)$ & $1(0.2)$ & $8(0.6)$ & $3(0.6)$ & $10(2.8)$ & $<0.001$ \\
\hline Atrial fibrillation & $282(10.2)$ & $7(1.4)$ & $159(11.2)$ & $64(13.7)$ & $52(14.5)$ & $<0.001$ \\
\hline Recent myocardial infarction & $1319(47.7)$ & $144(28.0)$ & $652(45.8)$ & 307 (65.9) & $216(60.2)$ & $<0.001$ \\
\hline Previous PCl & $201(7.3)$ & $34(6.6)$ & $94(6.6)$ & $41(8.8)$ & $32(8.9)$ & 0.23 \\
\hline Previous cardiac surgery & $46(1.7)$ & $6(1.2)$ & $17(1.2)$ & $11(2.4)$ & $12(3.3)$ & 0.02 \\
\hline Left ventricular ejection fraction & & & & & & $<0.001$ \\
\hline $30-50 \%$ & $612(22.1)$ & $81(16.2)$ & $284(20.8)$ & $131(29.2)$ & $116(33.7)$ & \\
\hline$<30 \%$ & $87(3.1)$ & $4(0.4)$ & 39 (2.9) & $28(6.3)$ & $16(4.7)$ & \\
\hline Critical preoperative status & $217(7.9)$ & $12(2.3)$ & $81(5.7)$ & $62(13.3)$ & $62(17.3)$ & $<0.001$ \\
\hline \multicolumn{7}{|l|}{ Operative data } \\
\hline Type of operation & & & & & & $<0.001$ \\
\hline Elective & $1260(45.6)$ & $340(66.1)$ & $688(48.3)$ & $115(24.7)$ & $117(32.6)$ & \\
\hline Urgent & $1306(47.3)$ & $173(33.7)$ & $677(47.5)$ & $289(62.0)$ & $167(46.5)$ & \\
\hline Emergency & $197(7.1)$ & $1(0.2)$ & $60(4.2)$ & $62(13.3)$ & 75 (20.9) & \\
\hline Mammary artery graft & $2642(95.6)$ & $508(98.8)$ & $1385(97.2)$ & $432(92.7)$ & $317(88.3)$ & $<0.001$ \\
\hline Potent antiplatelets within 5 days & $512(18.5)$ & $37(7.2)$ & $242(17.0)$ & $139(29.8)$ & $94(26.2)$ & $<0.001$ \\
\hline Off-pump coronary surgery & $1510(54.6)$ & $311(60.5)$ & 789 (55.4) & $230(49.4)$ & $180(50.1)$ & 0.01 \\
\hline Number of distal anastomoses & $4.0 \pm 1.1$ & $4.0 \pm 1.1$ & $3.9 \pm 1.1$ & $4.0 \pm 1.1$ & $3.8 \pm 1.0$ & 0.07 \\
\hline In-hospital death & $67(2.4)$ & $0(0,2)$ & $6(0.4)$ & $8(1.7)$ & $53(14.8)$ & $<0.001$ \\
\hline
\end{tabular}


Continuous variables are reported as mean and standard deviation. Categorical variables are reported as absolute number and percentages; eGFR: estimated glomerular filtration rate; PCl: percutaneous coronary intervention; OR: operating room. Definition criteria are according to EuroSCORE II. 
Table 2. E-CABG classification of postoperative complications or interventions for their treatment and their prevalence. Adjusted risk estimates for postoperative early and late mortality are reported.

\begin{tabular}{|c|c|c|c|c|c|}
\hline Grades & $\begin{array}{l}\text { Postoperative complications or interventions } \\
\qquad \text { for their treatment }\end{array}$ & $\begin{array}{l}\text { Additive } \\
\text { score }\end{array}$ & No. (\%) & $\begin{array}{l}\text { Adjusted } \\
\text { analysis for } \\
\text { mortality } \\
H R(95 \% \mathrm{Cl})\end{array}$ & $\begin{array}{l}\text { Multiple } \\
\text { propensity score } \\
\text { adjusted analysis } \\
\text { for mortality }\end{array}$ \\
\hline
\end{tabular}

Grade 0

None of the below mentioned

0

$514(18.6)$

Reference

category

Reference

complications/interventions

$1425(51.6)$

$1.76(1.11-2.78)$

$1.69(1.06-2.68)$

Grade 1

Postoperative use of antibiotics

2

937 (33.9)

Atrial fibrillation

2

$1186(42.9)$

Transfusion of platelets

2

826 (29.9)

Transfusion of fresh frozen plasma or Octaplas

3

$738(26.7)$

Transfusion of 2-4 units of RBC

3

$939(34.0)$

Deep wound infection of the leg

3

$78(2.8)$

Permanent pace-maker implantation

3

$18(0.7)$

Grade 2

$466(16.9)$

Pericardial fenestration for effusion

4

$47(1.7)$

Acute kidney injury (dialysis excluded)

4

$258(89.3)^{*}$

Transfusion of 5-10 units of RBC

5

$443(16.0)$

Reoperation for bleeding

5

$163(5.9)$

Deep sternal wound infection

5

$40(1.4)$

Postoperative IABP

5

$16(0.6)$

Grade 3

$359(13.0)$

$5.08(3.15-8.20)$

$4.57(2.81-7.43)$

Transfusion of $>10$ units of RBC

7

$68(2.5)$

Acute kidney injury requiring dialysis

7

$42(1.5)^{*}$

Mediastinitis

7

$43(1.6)$

Stroke

7

$58(21)$

CABG or $\mathrm{PCI}$ for technical failure 
Reoperation for hemodynamic instability

Ventricular fibrillation/asystole

Surgery for gastrointestinal complications

Postoperative ECMO
$168(6.1)$

49 (1.8)

$32(1.2)$

0

Definition criteria are according to the E-CABG criteria [10]; HR: hazard ratio; Cl: confidence interval; RBC: red blood cell; IABP: intra-aortic balloon pump; CABG: coronary artery bypass grafting; PCl: percutaneous coronary intervention; ECMO: extracorporeal membrane oxygenation; * patients on preoperative dialysis excluded from this analysis. 